\title{
O cuidado aos usuários com transtorno mental em tratamento com medicação de depósito: percepções da equipe saúde da família
}

\section{Care of mental patients undergoing treatment with slow release medications: perceptions of the family health team}

\author{
Jackeline Lourenço Aristides ${ }^{1}$; Brígida Gimenez Carvalho²; Dinarte Alexandre \\ Prietto Ballester ${ }^{3}$
}

\begin{abstract}
Resumo
A medicação de depósito vem sendo administrada em todas as unidades saúde da família de Londrina, com a finalidade de aumentar a adesão dos usuários com transtorno mental. O objetivo deste trabalho é apreender as percepções da equipe saúde da família na assistência ao usuário que faz uso da medicação de depósito. As informações foram obtidas por meio de grupo focal com estes profissionais e apreciadas por meio da análise de conteúdo. Pode-se abstrair que houve melhora do acesso depois da descentralização deste medicamento para as unidades, porém não houve consenso quanto ao aumento da autonomia dos usuários após a nova terapêutica. Quanto à desospitalização evidenciaram-se falas de preocupação quanto à socialização destas pessoas. Permearam-se falas de alienação e negação sobre a assistência prestada, assim como falas da falta de infraestrutura, recursos humanos e educação permanente. Pode-se perceber a necessidade do apoio matricial como forma de enfrentamento.
\end{abstract}

Palavras chave: Medicação de depósito. Saúde mental. Processo de trabalho. Saúde da família. Educação permanente.

\begin{abstract}
The depot medication has been administered in all family health units in Londrina, in order to increase compliance of users with mental disorder. The objective of this work is to understand the perceptions of family health team in assisting the user who makes use of depot medication. The information was obtained through focus group with these professionals and appreciated by content analysis. It is possible to abstract an improvement after the decentralization of access to this medicine units, but there was no consensus in relation to the increase of autonomy of users after the new therapy. As for deinstitutionalization became evident statements of concern about the socialization of these people. Permeated up lines of alienation and denial about the care provided, as well as statements of lack of infrastructure, human resources and continuing education. It can be seen the necessity of matrix support as a way of coping.

Key-words: Depot medication. Mental health. Work process. Family health. Permanent education.
\end{abstract}

\footnotetext{
${ }^{1}$ Enfermeira, Especialista em Saúde Mental (UEL), Especialista em Saúde da Família modalidade Residência Multiprofissional em Saúde da Família e Mestre em Saúde Coletiva (UEL). Contato principal para correspondência: jackeline.aristides@gmail.com.

${ }^{2}$ Docente do Departamento de Saúde Coletiva da Universidade Estadual de Londrina. E-mail: brigidagimenez@gmail.com.

${ }_{3}^{3}$ Docente do Departamento de Saúde Coletiva da Universidade Estadual de Londrina. E-mail: ballester.dinarte@gmail.com.
} 


\section{Introdução}

Segundo Amarante (2010), o paradigma psiquiátrico clássico transforma loucura em doença e produz uma demanda na sociedade por tratamento e assistência, afastando o louco do convívio social e transformando a loucura em objeto do qual o sujeito precisa distanciar-se para produzir saber e discurso.

Acrescenta ainda que, é justamente neste simbolismo que a prática e saber psiquiátricos tornam-se visíveis no manicômio. A "tradição basagliana", inspirada nas propostas de desospitalização e desinstitucionalização do psiquiatra italiano Franco Basaglia, traz em seu interior a necessidade de uma análise históricocrítica a respeito da sociedade e da forma com que esta se relaciona com o sofrimento e a diferença.

Com a Reforma Psiquiátrica, a centralidade passa a ser do "direito à convivência familiar e comunitária", onde a assistência às pessoas em sofrimento mental deixa de ser realizada gradativamente nos hospitais psiquiátricos para ganhar força na rede extra hospitalar. Assim, os casos mais leves deverão ser atendidos na própria Estratégia Saúde da Família (ESF), e casos mais graves pelos Centros de Atenção Psicossocial (CAPS).

Nesse contexto, a Estratégia Saúde da Família (ESF) trabalha na perspectiva do indivíduo e família, justamente onde se encontra a essência do trabalho em saúde mental: o núcleo familiar. Na medida em que há a busca do atendimento das necessidades em saúde do indivíduo e de sua complexa rede familiar, esta estratégia de saúde se destaca como possível aliada na luta antimanicomial e na busca da cidadania e reinserção dos usuários com transtorno mental.

Para que este processo ocorra de forma a atender os princípios norteadores da atenção integral, o profissional da unidade saúde da família necessita de conhecimentos específicos e abrangentes, de forma a promover o acolhimento do usuário com transtorno mental e família prevenir a cronicidade dos agravos e a necessidade das internações hospitalares.

Conforme Lucchese et al. (2009), articulações entre a ESF e a atenção à saúde mental na lógica da Reforma Psiquiátrica podem ocorrer, uma vez que ambos têm princípios e diretrizes que convergem: a busca em romper com o modelo médico hegemônico, o desafio de tomar a família em sua dimensão sócio-cultural como objeto de atenção, de planejar e executar ações num determinado território, promover cidadania/participação comunitária, e constituir novas tecnologias para melhoria da qualidade de vida das pessoas.

Segundo Oliveira et al. (2003), os antipsicóticos de depósito são um recurso terapêutico útil em situações em que a manutenção de uma terapia farmacológica diária via oral é impossibilitada ou indesejada. Sabe-se que a aderência ao tratamento das psicoses é um problema frequente, devido a inúmeros fatores entre os quais se encontram os importantes efeitos colaterais dos medicamentos utilizados, necessidade de administração continuada e a própria natureza dos transtornos psicóticos, que levam o usuário muitas vezes a recusar-se a ingerir a droga prescrita. A medicação neste caso pode ser feita quinzenalmente ou mensalmente, garantindose o tratamento do usuário. Esta opção é sugerida quando o sujeito já fez uso de medicamento via oral.

Conforme Peres e Figueiredo (2004), a medicação de depósito é utilizada em clientes que apresentam sintomas psicóticos, a fim de evitá-los. Algumas vantagens são atribuídas ao seu uso, por ser uma droga injetável, nos dá a certeza da dose administrada, o que difere da medicação oral, que , muitas vezes, é desprezada pelo cliente, e pelo seu efeito de longa duração, possibilitando intervalos de administração que variam entre 15 e 30 dias.

Segundo Oliveira et al. (2003), esse tratamento mostra-se como uma ferramenta bastante importante e eficaz na medida em que estudos apontam que a maioria dos indivíduos em regime de aplicação de 
depósito que mantinham boa adesão apresentava menos hospitalizações, em contraposição àqueles que não faziam este tipo de tratamento.

Dessa forma, estudos que apontam novas terapêuticas para minimizar o sofrimento psíquico, e levantam perspectivas de abordagem na equipe saúde da família são importantes no resolução dos obstáculos que a reforma psiquiátrica enfrenta para sua consolidação. E, para este enfrentamento, o apoio matricial mostra-se como ferramenta indispensável, assim como a educação permanente. Considera-se o como retaguarda na assistência à saúde mental aos trabalhadores da equipe saúde da família, e provê-se apoio especializado aos problemas de saúde, e à educação permanente como possibilitadora de reflexão e mudanças de práticas no processo de trabalho.

O apoio matricial, segundo Dimenstein et al. (2009), como a incorporação das ações em saúde mental na atenção básica como prioridade no cenário atual. Nesse sentido, o Ministério da Saúde propõe a estratégia do apoio matricial para facilitar o direcionamento dos fluxos da rede, promovendo uma articulação entre os equipamentos de saúde mental e as Unidades Básicas de Saúde. Surgiu após a verificação de que a Reforma Psiquiátrica não pode avançar se a Atenção Básica não ser incorporada ao processo. Sabemos que as equipes da atenção básica se sentem desprotegidas, sem capacidade de enfrentar as demandas em saúde mental que chegam cotidianamente ao serviço, especialmente os casos mais graves e ou crônicos.

Como mais uma terapêutica na assistência em saúde mental, a medicação de depósito é uma inovação e vem sendo utilizada com êxito em vários países. A equipe do centro de atenção psicossocial (CAPS III) de Londrina foi ousada quando apostou na proposta, e puderam ser beneficiados tanto os usuários que não aderiam ao tratamento medicamentoso e faziam acompanhamento no CAPS, quanto aqueles que estavam mais próximos às unidades saúde da família (USF). Dessa forma, estes últimos não mais precisariam se deslocar até o CAPS, já que a medicação de depósito é repassada mensalmente às USF, o que facilita o acesso e melhora a adesão.

O objetivo desta pesquisa é apreender as percepções de enfermeiros, auxiliares de enfermagem e agentes de saúde de uma equipe de saúde da família sobre a assistência ao usuário que faz uso da medicação psicotrópica de depósito, considerando as multiplicidades e subjetividades do processo de trabalho.

\section{Material e métodos}

Trata-se de um estudo qualitativo em que foram discutidas as percepções dos profissionais de saúde de uma unidade de saúde da família a respeito da assistência prestada aos usuários com transtornos psíquicos em uso da medicação de depósito.

A técnica para a coleta de dados foi a do grupo focal, que, segundo Kitzinger apud Backes et al. (2011), baseia-se numa entrevista em grupo, na qual a interação configura-se como parte integrante do método. No processo, os encontros grupais possibilitam aos participantes explorarem seus pontos de vista, a partir de reflexões sobre um determinado fenômeno social.

Conforme Melo e Araújo (2010), o grupo focal pode atingir um nível reflexivo que outras técnicas não conseguem alcançar, revelando dimensões de entendimento que, frequentemente, permanecem inexploradas pelas técnicas convencionais de coleta de dados. O trabalho com grupos focais permite compreender os seguintes aspectos: processos de construção da realidade por determinados grupos sociais, práticas cotidianas, ações e reação a fatos e eventos, comportamentos e atitudes.

Assim, conforme estas autoras, ele constitui uma técnica importante para o conhecimento das representações, percepções, crenças, hábitos, valores, restrições, preconceitos, linguagens e 
simbologias prevalentes no trato de uma dada questão por pessoas que partilham alguns traços em comum, relevantes para o estudo do problema visado.

Segundo Minayo et al. (1998), a análise de conteúdo abrange as seguintes fases: pré-análise, exploração do material, tratamento dos resultados obtidos e interpretação. Na primeira fase, é feita uma leitura do material, no sentido de se entrar em contato com sua estrutura, descobrir orientações e registrar impressões sobre a mensagem; na segunda, há leitura exaustiva e aplicação daquilo que foi definido na fase anterior; na terceira, tentouse desvendar o conteúdo subjacente ao que está sendo manifesto, devendo-se buscar ideologias, tendências e outras determinações características dos fenômenos que estão sendo estudados.

Ainda com esta autora o critério para a amostra é, então, não numérico, considerando que uma amostra ideal é aquela capaz de refletir a totalidade nas suas múltiplas dimensões, ou seja, a constituição do número de entrevistas tem como base o método da exaustividade, que se finaliza na medida em que se consegue contemplar todos os aspectos levantados no roteiro (MINAYO et al., 1998).

Minayo (1992) pontua que a análise de conteúdo tem como objetivo a verificação de hipóteses e/ou questões, para encontrar respostas para as questões formuladas e também para podermos confirmar ou não as afirmações estabelecidas antes do trabalho de investigação (hipóteses). A outra função diz respeito à descoberta do que está por trás dos conteúdos manifestos, e vai além das aparências do que está sendo comunicado.

\section{Local do estudo}

A pesquisa foi realizada em unidade saúde da família da região norte da cidade de Londrina, que possui uma área de abrangência de cerca de 18.000 habitantes e conta com três equipes saúde da família. A relação da unidade com o Centro de Atenção Psicossocial se dá apenas em encontros isolados para discussão de casos mais complexos, não há uma relação mais permanente que promova o apoio matricial. Nessa unidade, tive a oportunidade de fazer Residência Multiprofissional em Saúde da Família e atuar como enfermeira residente em uma equipe.

\section{Sujeitos da pesquisa}

Participaram do grupo focal, um representante sorteado de cada equipe saúde da família e um representante sorteado de cada categoria profissional, sendo esses agentes comunitários de saúde, auxiliares de enfermagem e enfermeiros, somando seis participantes. A única categoria não representada foi a do médico, que na hora agendada do grupo focal não pôde participar por ter tido uma emergência em outra unidade que precisou atender.

\section{Coleta de dados}

O grupo focal foi realizado no mês de agosto de 2008 com seis profissionais de saúde. As questões geradoras de discussão no grupo focal foram as seguintes: "Qual a importância da medicação de depósito para você, para o usuário e sua família?", "Quais as facilidades e dificuldades encontradas por você no cuidado ao usuário de medicação de depósito e sua família?” E, por fim as considerações finais de cada participante. Foi realizado apenas um encontro, previamente agendado com todos os profissionais sorteados, quem conduziu o processo do grupo focal foi a autora principal, residente em saúde da família nesta mesma unidade.

As falas dos participantes do grupo focal foram gravadas e transcritas, e a fita após sua transcrição em papel foi inutilizada. Para a interpretação dos dados, foi utilizada a análise de conteúdo que tem como funções a descoberta do que está por trás dos conteúdos manifestos, indo além das aparências do que está sendo comunicado.

\section{Aspectos éticos}

Esta pesquisa foi aprovada de acordo com as normas relativas à pesquisa envolvendo seres humanos da resolução 196/96 do Conselho Nacional de Saúde, por meio do processo no 
16463/2008 do Comitê de Ética em Pesquisa da Universidade Estadual de Londrina. Os integrantes foram informados dos objetivos desta pesquisa, concordaram em participar e assinaram o Termo de Consentimento Livre e Esclarecido.

\section{Resultados e discussão}

$\mathrm{Na}$ análise de conteúdo, pôde-se identificar duas categorias centrais, uma relacionada ao próprio usuário em uso da medicação de depósito e família, e outra arrolada ao processo de trabalho dos profissionais em assistência direta a estes usuários. Destacamos que na primeira categoria sobressaíram três subcategorias: autonomia e mudanças na vida do usuário em uso de medicação de depósito, família, e acessibilidade. Da categoria do processo de trabalho emergiram três subcategorias: significados da assistência prestada, infraestrutura da unidade saúde da família e educação permanente.

Importância da medicação de depósito para o usuário e família na perspectiva da equipe saúde da família

Esta categoria foi subdividida em três subcategorias:

1) Autonomia e mudanças na vida do usuário em uso de medicação de depósito

Conforme Almeida, Dimenstein e Severo (2010) uma vez tendo comprometida sua razão, olouco tornase inábil para gerir sua vida: essa responsabilidade teria de ser entregue a outrem, seja o Estado, seja o médico, seja o familiar, assim restou o silêncio e a incapacidade. Porém, os movimentos reformistas no campo da saúde mental, vêm buscando interferir e transformar essa lógica, especialmente no que diz respeito ao empoderamento às pessoas com transtornos mentais e o incremento de seu poder de contratualidade na sociedade. As propostas de reabilitação psicossocial passam pelo exercício da autonomia e cidadania e visam à inserção de pessoas secularmente estigmatizadas.

$\mathrm{Na}$ frase a seguir, o profissional da unidade saúde da família menciona mudanças na autonomia, na qualidade de vida e no cotidiano das pessoas que sofrem de transtorno mental e fazem uso da medicação de depósito.

E1: "Enquanto paciente, ele trabalha, ele desenvolve todas as atividades de casa, ele consegue ir ao banco, tudo isso ele não fazia, ele era assim um "lixo", agora, ele voltou ao mundo real, consegue ir ao banco, trabalha, faz tudo...".

Em relação à percepção do tratamento para os usuários, não foi manifestada concordância sobre essa questão entre os profissionais. Para alguns, são pessoas com falta de autopercepção sobre o tratamento, e também não demonstram importância dessa questão. Para outros, muitos desses usuários compreendem a importância do tratamento e fazem uma adesão consciente à proposta terapêutica.

\section{E1: “...Agora enquanto paciente, não dá para dizer, porque eles não sabem relatar, então, para a gente está resolvido" \\ E6: “É, uma coisa assim, eu penso, igual a ... falou que o paciente às vezes não sabe, eu acho que tem muitas que sabem a importância, porque eles procuram a unidade, tem muitos que eles mesmos vem tomar aqui, né...?"}

Segundo Almeida, Dimenstein e Severo (2010), o empoderamento é concebido não como a transferência de responsabilidades ou mero usufruto de benefícios por usuários e familiares, mas como o aumento da capacidade de eleição e ação: enxergaos como coprodutores de políticas, por meio da corresponsabilização com diversos atores e do trabalho em rede entre diferentes instâncias sociais.

2) A Família e o processo de desospitalização

É pontuada também pelo profissional a questão dos indivíduos em sofrimento psíquico que "voltaram para a casa" após o processo de desospitalização, e cuja família muitas vezes não foi amparada pela rede institucional com relação ao cuidado. Esse fato também foi colocado em outro momento por um dos entrevistados quando se refere à incapacidade da família em agir em casos de agressividade.

\footnotetext{
E1: "Eu acho que tem que manter, melhorar, eu acho
} 
que tem muito o quê fazer, né? E, que bom que eles mudaram a mentalidade deles de achar que acabam a internação de psiquiatria, de volta para casa, o programa de volta para casa, e a família que resolva o problema, então, se é de volta para casa, então, bem estruturado, né?

E1: "Mas, às vezes a familia tão pouco pode fazer, dependendo do grau do paciente, a família pouco pode fazer, porque, a gente sabe que tem paciente que tem que vir até a polícia para segurar, né?

A profissional acima fez referência ao programa "De volta para casa", criado pelo Ministério da Saúde, que trata de reintegração social de pessoas acometidas de transtornos mentais, egressas de longas internações, que tem como parte integrante o pagamento do auxílio reabilitação-social.

Em sintonia com Almeida, Dimenstein e Severo (2010), especificamente no campo da saúde mental e na Estratégia da Atenção Psicossocial, a perspectiva da desinstitucionalização implica a ampliação das estratégias de vida e pertencimento de usuários para além do campo sanitário, exigindo a diversificação dos espaços de socialização.

Outro fato importante é que a responsabilização pelo cuidado dessas famílias é tanto da equipe de saúde mental quanto da saúde da família, o que pode ser conseguido por meio do matriciamento.

De acordo com o Ministério da Saúde (CHIAVERINI, 2011), o matriciamento constitui uma nova possibilidade de atendimento aos usuários em seu próprio território. Uma vez valorizados o modelo interdisciplinar e a parceria, torna-se possível a realização de atividades pelos diversos tipos de profissionais de acordo com o projeto terapêutico singular.

\section{3) Acessibilidade do usuário}

A adesão à medicação de depósito é maior quando o acesso geográfico é facilitado, ou seja, a distribuição deste tipo de tratamento nas unidades saúde da família facilita a adesão. A falta de acesso ao transporte se torna uma variável que dificulta a locomoção do indivíduo com transtorno mental pela família, e no caso da descentralização para as unidades, este usuário pode se locomover sozinho à unidade saúde da família para a realização da injeção de depósito.

E5: "Para a família melhorou assim, porque mora perto do posto, é mais fácil de tomar, porque o caps é longe da família ir levar né? Tem dificuldade de levar né? E, eles próprios está podendo vir sozinho tomar né?"

É importante também pontuar aqui, que não basta haver o medicamento à disposição nas unidades saúde da família, mecanismos devem ser criados para que também haja acesso organizacional, ou seja, que a equipe saúde da família também esteja preparada para dar esta assistência.

Conforme o Ministério da Saúde (CHIAVERINI, 2011), alguns trabalhos focam o problema da adesão nos pacientes, outros nos médicos e outros nos sistemas de saúde. A visão de maior utilidade é a multidimensional, em que todos os fatores são determinantes (a frase está incompleta).

3.1) Processo de trabalho dos profissionais da unidade saúde da família em assistência direta ao usuário de medicação de depósito

Como explicitado anteriormente, esta categoria será dividida em subcategorias: os significados da assistência prestada aos usuários em uso de medicação de depósito, infraestrutura da unidade saúde da família e educação permanente. Nestas categorias, aparecerão falas carregadas de sentimentos dos profissionais de saúde, que vão desde demanda, alienação, sobrecarga de trabalho até a negação, sentimentos decorrentes da escassez da educação permanente e da falta de infraestrutura da unidade.

3.2) Significados da assistência prestada aos usuários em uso medicação de depósito

Nesta subcategoria, abordam-se os significados da assistência ao usuário em tratamento com medicação de depósito, demonstrando falas com boas expectativas em relação a este novo tratamento para o usuário, até percepções como mais demanda 
de trabalho para a unidade. Na frase a seguir, há menção da importância desta medicação para o setor público, especificamente para a saúde da família e centro de atenção psicossocial (CAPS) no que se refere à adesão do paciente ao tratamento.

E1: "Bom, o que eu acho que para o usuário e para o profissional de saúde né? Para o profissional eu acho que é muito bom, acho que facilita muito, nosso trabalho enquanto saúde pública, enquanto saúde da família, porque... a gente que né que, na maioria das vezes esses pacientes, são pacientes rebeldes, eles não aceitam a medicação, não faz uso correto, nem sempre tem um cuidador constantemente com esse, paciente que pode, possa estar dando a medicação correta, então acho que isso vem facilitar muito né? O trabalho acho que de todo mundo né? Acho enquanto unidade, enquanto psf, enquanto caps...

Apesar dos benefícios reconhecidos pela equipe ao usuário, referem que a medicação se torna mais uma demanda para a unidade e de mais trabalho a ser desempenhado no dia-a-dia. Talvez esse fato se deva ao fato de essa tarefa vir sendo desempenhada de forma "automatizada" e "solta" dentro do processo de trabalho, o que revela desconhecimento de sua importância.

E3: “... Melhorou? Em que sentido?... de mais serviço?... Ué, mais demanda para o posto, mais demanda para o posto, isso que eu penso, melhorar em que termos você fala?"

E2: "Para a família é... para a família melhorou, agora para nós é mais serviço, mais demanda... porque a gente tem que levar lá...”.

Para Marçal, Campos e Furtado (2007), os velhos problemas dificultam essa discussão, principalmente no diálogo com muitos dos trabalhadores que não conseguem refletir acerca das especificidades do trabalho em saúde pública, não permitindo um olhar sobre a demanda, que é sempre maior do que a oferta da assistência, no modelo de consumo de procedimentos de saúde no qual o Brasil está contextualizado. Ao mesmo tempo em que isso ocorre, existe a autonomia dos profissionais na micropolítica do trabalho, todos eles carregam consigo histórias de vida e pré-concepções do mesmo.

Esse encontro de autonomias só poderá ser possível na medida em que os gestores permitirem a existência de espaços de reflexão do processo de trabalho. A fala a seguir demonstra a dificuldade dos profissionais de saúde na aceitação da assistência na unidade saúde da família dos usuários com transtorno mental. Aceitam porque estes fazem parte da população adscrita da unidade e "se não aceitarmos, quem vai aceitá-los?".

E2: "Nós do posto que tem que assumir porque, se nós não assumir, quem..."

Em relação ao tratamento, não há resultados imediatos. A loucura de um membro da família tende a circular entre todos os outros e a precariedade da situação de vida de grande parte das pessoas contribui para o adoecimento. No entanto, nota-se que o olhar voltado ao grupo familiar e ao contexto social têm resultados mais positivos do que aquele que reduz o sujeito à sua doença. $\mathrm{O}$ trabalho conjunto (e principalmente com o agente comunitário) enriquece a prática, desmistifica preconceitos, aproxima e modifica territórios. É possível e necessário que a atenção básica encarregue-se da saúde mental.

\section{3) Infraestrutura da unidade saúde da família}

Quando se fala em assistência ao usuário que faz uso de medicação de depósito, a falta de infraestrutura da unidade tornou-se um dos argumentos para a dificuldade no trabalho:

E3: "Pelo amor de Deus não dá, não temos estrutura para aquilo"... (burburinhos)... "Nós não temos estrutura para aquilo, não, não tem condições."

A expressão da falta de infraestrutura nos dá logo a conotação da falta de salas adequadas, equipamentos e veículos para o deslocamento, porém, nos remete também às subjetividades do cotidiano dos profissionais, que se sentem sobrecarregados com a demanda do trabalho. Esse sentimento se deve ao fato de que a atenção básica, entrada preferencial dos usuários no sistema de saúde, se vê a cada dia imersa em novos conhecimentos e demandas, assim há a sobrecarga dos profissionais que nela atuam. É importante também ressaltar que a maior parte dos programas estão dirigidos à atenção básica, e as equipes saúde da família são a "via final comum" ou 
o "braço efetor" de praticamente todas as políticas setoriais produzidas no Ministério da Saúde.

Conforme Delfini et al. (2009), as demandas de saúde mental são sempre muito complexas. Muitas vezes é difícil lidar sozinho com situações de intenso sofrimento, os próprios agentes relatam essa solidão no trabalho. É preciso, então, compartilhar essas vivências e responsabilidades com outros atores e até outros serviços.

\section{4) Educação permanente}

Segundo Carotta, Kawamura e Salazar (2009), a educação permanente em saúde tem como ferramentas aquelas que buscam a reflexão crítica sobre a prática cotidiana dos serviços de saúde, possibilitando mudanças nas relações, nos processos, nos atos de saúde e nas pessoas. Outras potencialidades dessa estratégia são o fortalecimento do controle social, a repolitização do Sistema Único de Saúde (SUS), o incentivo ao protagonismo de usuários e trabalhadores no processo saúde e doença e a produção de um impacto positivo sobre a saúde individual e coletiva da população.

Ainda com esses autores, a Política Nacional de Educação Permanente em Saúde (EPS) possibilita a identificação das necessidades de formação e de desenvolvimento dos trabalhadores da área da saúde e a construção de estratégias e processos que qualifiquem a atenção e a gestão, fortalecendo o controle social. Considerando que a educação permanente contempla também a reflexão e técnica competente, pode-se observar que nesta subcategoria a escassez de atividades educativas com o enfoque da Educação Permanente em Saúde - EPS compromete o desenvolvimento do trabalho da equipe. Este comprometimento vai desde o desconhecimento da medicação de depósito pelos trabalhadores, até a dificuldade de abordagem ao usuário em sofrimento psíquico nas emergências psiquiátricas. Nesse sentido, a terapêutica da medicação de depósito talvez não seja novidade para a equipe de saúde mental, mas para os profissionais da equipe saúde da família a administração de doses diferenciadas a cada usuário transmite insegurança. $\mathrm{O}$ fato de se realizar uma ampola de um medicamento injetável é "até certo ponto" aceitável em termos de administração, mas as falas abaixo demonstram que a realização de duas, três ou quatro ampolas em intervalos variados, na percepção da equipe da enfermagem tem a conotação de superdosagem. Dessa forma, a educação permanente destes trabalhadores seria essencial para o conforto e segurança da equipe e do usuário.

E1: "Nunca tive treinamento... despejaram...”.
E3: “Colocaram num sacão preto, toma aqui o
remédio... (tempo) E, tem um que é quatro ampolas, de
uma ampola tudo bem.... rs, é cinco ampolas, porque
aquele negócio está muito confuso, aquele papel está
muito confuso, o papel, se você pegar você vê assim,
aí parece, aí parece, você tem pessoas que você faz
daqui quatro semanas, né? Observar quatro semanas,
aí tem gente que você faz quatro ampolas daqui um
mês, rs, uma semana é um mês, virou confuso, mas,
depois, entrou tudo no eixo, certinho".
E6: “... Eu acho que quando você tem um
conhecimento daquilo que você está fazendo se torna
muito mais fácil... Às vezes o paciente está aí e você
tem que estar... saber o quê fazer...”.

$\mathrm{Na}$ frase seguinte relatam a importância da educação permanente antes da implantação de um projeto:

E3: "Eu acho que antes deles fazerem isso eles deveriam ter dado treinamento para nós.".

Administrar um medicamento sem conhecer seu princípio ativo, função e efeitos colaterais deixa a equipe insegura e a predispõe aos erros, permitindo que o cuidado seja apenas procedimental. Ao final do grupo focal, a inquietação geral foi a saber qual a função e os efeitos colaterais da medicação de depósito. Ao saberem do efeito colateral da "impregnação", os profissionais sentiram-se no dever de informarem a família com relação aos cuidados pós a administração da medicação de depósito.

E3: “... E a gente não sabe não, por exemplo, a dipirona que a gente sabe que é antitérmico, analgésico, tá".

E3: "Nada, nada, nada, a gente faz parecendo uma máquina está feito e acabou..."

E3: "Lógico que é , não sabe que reação que dá, pode dar uma injeção dessa, que reação que pode dar? Eu 
posso realmente fazer a injeção? E, ficar tranqüila que o paciente vai embora tranquilamente, nada vai acontecer?.

É de fundamental importância que os usuários compreendam as informações acerca do tratamento, tais como os riscos e benefícios inerentes ao mesmo, porém o que se observa é que isto não vem ocorrendo com relação aos efeitos colaterais da medicação de depósito.

$\mathrm{Na}$ fala a seguir, notamos que a falta de um profissional de enfermagem do sexo masculino na unidade para o atendimento aos usuários com transtornos mental e com comportamento agressivo, está mais relacionada à pouca capacitação em emergência psiquiátrica.

E1: “... Porém, né? Eu acho que é uma função ainda que do caps, se é uma... se é um paciente calmo, dá para a unidade fazer, agora se é um paciente agressivo, no caso de "fulano" aí, como é que é o nome daquele? ... Esquizofrenia, esquizofrenia!, não adianta, porque a nossa unidade, nós não temos nenhum auxiliar do sexo masculino, não temos nenhum enfermeiro do sexo masculino, e não adianta falar porque, enfermeira e auxiliar não dão conta, então tem coisa que dá para passar pela unidade, outras acho que o caps tem que assumir, tendo uma, assim, funcionário ou não ele tem que assumir, né?"

São expressos nestas falas os casos em que os auxiliares necessitam de deslocamento até o domicílio para a realização da medicação de depósito. Observa-se também que o imaginário dos profissionais está impregnado pelo estigma com relação ao usuário com esquizofrenia imaginandoos sempre violentos.

E1: "A polícia vem, já tem todo um esquema, né? Segura no braço, vira, a pessoa fica imobilizada com aquilo, aí, o profissional vem e aplica, pronto... Tem que correr risco"

Foi colocado pelos profissionais que existia no município um serviço móvel que fazia o transporte dos usuários em surto franco, porém não havia naquela época o programa da medicação de depósito. Há hoje casos complexos que são ainda acompanhados pelo caps no que diz respeito à realização da medicação de depósito em ambiente domiciliar.
E1: "Antigamente tinha o TEC, não era? Ele vinha, levava...”.

A abordagem aos indivíduos em emergência psiquiátrica deve ter a integração do CAPS, Unidade Saúde da Família e SAMU (Serviço de Atendimento Móvel de Urgência). Quando o usuário tem comportamento mais agressivo, e foge a atual capacitação dos profissionais da saúde da família, o que tem ocorrido é a participação dos profissionais do CAPS III na realização da medicação de depósito em domicílio, e nos casos de emergência psiquiátrica o usuário é atendido por um serviço móvel (SAMU).

A Educação permanente vem gradativamente ocorrendo entre estes serviços, principalmente com a construção de um protocolo de emergência psiquiátrica que servirá de norteador das ações em saúde mental. Deve-se ter em mente que não se trata de "caso de polícia", porque não é com medida repressiva que a contenção será conseguida.

E1: "Hoje, você pode chamar a polícia, a polícia vai à maioria dos casos... você chama ela vai, você só vai e aplica... o samu que deveria ir não vai..."

\section{Considerações finais}

De todo conteúdo abstraído, pode-se primeiramente observar os significados que os profissionais atribuem ao uso da medicação de depósito pela pessoa com comprometimento psíquico: autonomia e mudanças positivas no cotidiano destas pessoas. Outros profissionais também demonstraram idéias discordantes, na medida em que pontuaram a falta de autopercepção e compreensão da importância do tratamento pelas pessoas em sofrimento psíquico. E, isso se deve muitas vezes por "pré-conceitos" e mitos que estes trabalhadores carregam do imaginário coletivo, que tratam estes usuários como "doentes mentais".

Quando abordadas as mudanças que os profissionais viam na família após a introdução deste novo medicamento, o que ficou bastante 
claro foi o fato de que houve diminuição da agressividade, porém é destacada também a questão da responsabilização da família no cuidado. Esse envolvimento familiar na assistência ao usuário com doença mental é um processo difícil, e até mesmo a sociedade ainda não está preparada para o convívio comunitário, daí a importância do apoio da rede de saúde como um todo neste processo de cuidado e socialização.

Ainda para o usuário percebe-se também que o acesso a esta nova terapêutica foi facilitado pela disposição da medicação de depósito nas próprias unidades básicas.

Quanto ao processo de trabalho, este é descrito por meio de obstáculos enfrentados na assistência prestada às pessoas em uso de medicação de depósito, a deficiência de infraestrutura e educação permanente. Vários sentimentos emergiram dos profissionais quanto ao cuidado a estas pessoas, mais "demanda" para a unidade, alienação e dificuldade na aceitação de mais um programa de saúde. Todos os discursos parecem conduzir para a pouca aproximação que possuem na abordagem em saúde mental, o que torna o cuidado meramente procedimental. Outra categoria demonstra a percepção sobre a falta de infraestrutura das unidades saúde da família para esta nova demanda, e esta não diz respeito somente à questão material, mas também às dificuldades emocionais e cognitivas que possuem na assistência em saúde mental.

Embora, a educação permanente apareça em outra categoria, não foi possível separar esta temática de outras categorias, pois todas elas convergem para um problema em comum. Ao terem pouco acesso às indicações deste novo medicamento, às reações adversas, e da abordagem em emergência psiquiátrica, os profissionais estão sujeitos, como já foi dito, ao desinteresse, alienação e desresponsabilização, embora se perceba sempre o desejo de aprender dos mesmos. No momento em que existem espaços de educação permanente, o acesso às novas informações técnicas, e até mesmo expressão de sentimentos por parte da equipe são possibilitados. Q quando isto ocorre pode-se concluir que um dos objetivos da educação permanente foi conseguido, que é o da reflexão do processo de trabalho.

Apesar de todas as dificuldades aqui apresentadas, é perceptível que a medicação de depósito veio para ficar e tem seu lugar no processo de trabalho da unidade. Também se pode perceber a preocupação dos profissionais com relação à qualidade de vida do usuário e família, muitos tem a compreensão de que a saúde mental tem como plano de fundo a saúde pública.

Percebe-se que a educação permanente e o apoio matricial são nós críticos para a atenção básica e saúde mental. Vimos que sem este enlace os avanços são lentos rumo à desospitalização e à reforma psiquiátrica.

\section{Agradecimentos}

A escrita e revisão do artigo foram realizadas pelas duas primeiras autoras, revisão e contribuições sobre a reforma psiquiátrica são do terceiro autor. Os agradecimentos vão aos profissionais da equipe saúde da família que gentilmente participaram do grupo focal.

\section{Referências}

ALMEIDA, K. S.; DIMENSTEIN, M.; SEVERO, A. K. Empoderamento e atenção psicossocial: notas de uma associação de saúde mental. Interface: Comunicação, Saúde, Educação, Botucatu, v. 14, n. 34, p. 577-89, jul./ set. 2010. Disponível em: <http://www.scielo.br/pdf/ icse/v14n34/aop1410.pdf>. Acesso em: 30 jun. 2012.

AMARANTE, P. Loucos pela vida: a trajetória da reforma psiquiátrica no Brasil. 2.ed . Rio de Janeiro: Fiocruz, 2010.

BACKES, D. S.; COLOMÈ, J. S.; ERDMANN, R. H.; LUNARDI, V. L. Grupo focal como técnica de coleta e análise de dados em pesquisas qualitativas. O Mundo 
da Saúde, São Paulo, v. 35, n. 4, p. 438-442, 2011. Disponível em <http://bvsms.saude.gov.br/bvs/artigos/ grupo_focal_como_tecnica_coleta_analise_dados_ pesquisa_qualitativa.pdf $>$. Acesso em: 28 ago. 2012.

CAROTTA, F.; KAWAMURA, D.; SALAZAR, J. Educação permanente em saúde: uma estratégia de gestão para pensar, refletir e construir práticas educativas e processos de trabalhos. Saúde e Sociedade, São Paulo, v. 18, jan./mar. 2009. Disponível em: <http:// www.scielo.br/scielo.php?script=sci_arttext\&pid $=$ S0104-12902009000500008>. Acesso em: 29 mar. 2012.

CHIAVERINI, D. H. (Org.). Guia prático de matriciamento em saúde mental. Brasília: Ministério da Saúde, 2011. Disponível em <http://www.unisite.ms.gov. br/unisite/controle/ShowFile.php?id=101002>. Acesso em: 5 jan. 2012.

DELFINI, P. S. S.; SATO, M. T.; ANTONELI, P. P.; GUIMARAES, P. O. S. Parceria entre CAPS e PSF: o desafio da construção de um novo saber. Ciência \& Saúde Coletiva, Rio de Janeiro, v. 14, set./out. 2009. Disponível em: $\quad<$ http://www.scielo.br/scielo.php?pid=S1413$81232009000800021 \&$ script $=$ sci_arttext $>$. Acesso em: 30 ago. 2012.

DIMENSTEIN, M.; SEVERO, A. K.; BRITO, M.; PIMENTA, A. L.; MEDEIROS, V.; BEZERRA, E. $\mathrm{O}$ apoio matricial em Unidades de Saúde da Família: experimentando inovações em saúde mental. Saúde e Sociedade, São Paulo, v. 18, n. 1, p. 63-74, 2009.

LUCCHESE, R.; OLIVEIRA, A. G. B.; CONCIANI, M. E.; MARCON, S. R. Saúde mental no Programa Saúde da Família: caminhos e impasses de uma trajetória necessária. Cadernos de Saúde Pública, Rio de Janeiro, v. 25, n. 9, set. 2009. Disponível em: <http://www. scielosp.org/scielo.php?script=sci_arttext\&pid=S0102$311 X 2009000900017 \&$ lang=pt\&tlng $=>$. Acesso em: 29 ago. 2012.

MARÇAL, C. R. M.; CAMPOS, R. O.; FURTADO, J. P. A saúde mental na atenção básica: uma saída para o sofrimento psíquico? Campinas, 2007. Disponível em: $<$ http://www.fcm.unicamp.br/grupos/saude_mental/ artigos/aprimorandos/1.pdf $>$. Acesso em: 15 mar. 2009.

MELO, P. S. L.; ARAÚJO, W. P. Grupo focal na pesquisa em educação. 2010. Disponível em <http://www.ufpi. br/subsiteFiles/ppged/arquivos/files/VI.encontro.2010/ GT.3/GT_03_10_2010.pdf \. Acesso em: 7 nov. 2012.

MINAYO, M. C. S. O desafio do conhecimento: pesquisa qualitativa em saúde. Rio de Janeiro: HUCITECABRASCO, 1992.

MINAYO, M. C. S.; DESLANDES, S. F.; CRUZ NETO,
O.; GOMES, R. (Org.). Pesquisa social-teoria, método e criatividade. 8. ed. Rio de Janeiro: Vozes, 1998.

OLIVEIRA, J. M.; BEZERRA, D. B.; FERNANDES, F. N.; MOTTA, G. L. C. L. Adesão ao tratamento e hospitalizações entre pacientes que realizam aplicações de Flufenazina Depot. Revista de Psiquiatria do Rio Grande do Sul, Porto Alegre, v. 25, n. 2, p. 312-17, ago. 2003. Disponível em: <http://www.scielo.br/pdf/rprs/ v25n2/v25n2a07.pdf>. Acesso em: 10 abr. 2008.

PERES, M. A. A; FIGUEIREDO, N. M. A. Grupo do NAP: atendimento ambulatorial ao cliente em uso de medicação de depósito- uma ação diferenciada de cuidar em psiquiatria. Texto \& Contexto Enfermagem, Florianópolis, v. 13, n. 4, p. 535-42, out./dez. 2004. Disponível em: <http://www.scielo.br/pdf/tce/v13n4/ a05.pdf>. Acesso em: 8 nov. 2012. 
